\title{
Calcium Hydroxide Nanoparticles and Hypogeum Environment: Test to Understand the Best Way of Application
}

\author{
Andrea Macchia, ${ }^{1}$ Ottavia Bettucci, ${ }^{2}$ Elisa Gravagna, ${ }^{2}$ Daniela Ferro, ${ }^{3}$ Romana Albini, \\ Barbara Mazzei, ${ }^{5}$ and Luigi Campanella ${ }^{6}$ \\ ${ }^{1}$ Syremont S.P.A., Largo Antonio Sarti n. 4, 00196 Rome, Italy \\ ${ }^{2}$ IA-CS, Italian Association of Conservation Scientists, Via T. Tasso 108, 00185 Rome, Italy \\ ${ }^{3}$ Institute for Nanostructured Materials Studies (ISMN-CNR), Aldo Moro Sq. 5, 00185 Rome, Italy \\ ${ }^{4}$ Chimici per unora Association, Via Bartolomeo Avanzini 31, 00163 Rome, Italy \\ ${ }^{5}$ Pontifical Commission for Sacred Archaeology, Palace of the Pontifical Institute of Christian Archaeology, \\ Via Napoleone III, 00185 Rome, Italy \\ ${ }^{6}$ Center of Sciences Applied to the Protection of Environment and Cultural Heritage- "Sapienza" University of Rome, \\ Piazzale Aldo Moro, 00185 Rome, Italy
}

Correspondence should be addressed to Elisa Gravagna; eli.gravi@gmail.com

Received 17 July 2013; Revised 4 December 2013; Accepted 5 December 2013; Published 20 January 2014

Academic Editor: Alan K. T. Lau

Copyright (C) 2014 Andrea Macchia et al. This is an open access article distributed under the Creative Commons Attribution License, which permits unrestricted use, distribution, and reproduction in any medium, provided the original work is properly cited.

For a long time the conservation of archaeological artefacts has been based on the principles of compatibility and minimal intervention. This involves a series of partially unsolved problems, concerning the products used for deteriorated structures consolidation. The choice of materials depends on several factors such as: microclimatic conditions, application methods, and reaction time of products. Recently the employment of nanolime in the consolidation treatments of decorative carbonate matrix surfaces had a great development, thanks to multifunctional use in calcium standard-sized particles treatments. However, while the use of the nanostructured materials is described in several specialized papers, the information about the best conditions of applicability of the nanolime and its related potentiality for the consolidation in hypogeum environment is rarely considered. The present work is devoted to represent a case study with the aim to give useful elements in order to evaluate the application of nanolime. The funerary inscriptions coming from St. Callixtus Catacombs have been the object of the research carried out in situ and in laboratory, checking indirectly in the short run and in the long run the porosity variation in the materials. The present study intends to indicate the best suspension concentration on consolidation in relationship with hypogeum environment.

\section{Introduction}

This work grows out from the need to develop consolidating treatments tailored for a specific archaeological structure [1] under hypogeal conditions [2]. Generically in a preventive conservation project, treatments and materials are always more frequently evaluated in order to provide two main requisites:

(a) minimal impact on the original structures [3], by respecting the antique execution techniques, the customary materials, and the history of the monument [4]; (b) highest durability, through the combination of complementary preventive activities, such as monitoring and adjusting environmental parameters and defining a monitoring and routine maintenance plan of the structures, together with graphic and photographic documentation, and the systematic data archiving, in order to easily compare the short-run and the longrun variations. Nanotechnologies and nanolime, as consolidating materials for architectural and stone surfaces [5], have been developed mainly in the last years, for the capability to solve several problems connected with conventional lime treatments, such as incomplete lime carbonation process, limited depth 
penetration, and the formation of thin white superficial layers [6]. The materials in nanodimensions have specific chemical and physical properties, linked to the physical and chemistry properties of very small particles with respect to the massive materials [7]. In these last years the nanolime has been applied widely, but despite the rapid increase in the literature on nanolime as a conservation material, it is today necessary to set up more technical and practical studies focalized on real specific cases. For practitioners, it is important to have a broader range of published case studies that describe the nanolime treatment to different environmental situation [4].

Consequently, it is necessary to analyze nanomaterials as a function of its specific application in order to carry out the best applying conditions according to expected results [8].

In general a hypogeum environment represents a complex situation [9], in fact in the specific of the St. Callixtus's catacomb, the site contains a great number of stone materials and wall paintings of great interest from historical, artistic, and religious point of view, by evidencing the necessity to be preserved, protected, and valued in situ. Both stone materials and wall paintings are chiefly made of calcium carbonate matrix (calcareous stones and plaster) aggregated in various structures. The deterioration phenomena are caused by microclimatic conditions and thermohygrometric exchanges between walls and the microclime and presence of light and visitors flow [10]. The combination of water, air, and light interaction with the artefacts structures activates several degradation processes, interesting the various degradation phenomena: cohesion, crumbling, pulverization, concretion and/or biological patina growth.

What has been described above induced us to consider the influence of relative humidity $(\mathrm{RH})$ and material's moisture content in the performance of stone consolidation [8]. Research carried out by El-Turki et al. [11] on lime pastes has shown that lime pastes exposed to $97 \% \mathrm{RH}$ are resulted to have a higher carbonation rate compared with pastes exposed to $65 \% \mathrm{RH}$, where a small amount of calcium hydroxide was retained.

The same authors [12] have also studied the strong influence of both relative humidity and particle size on the carbonation rates of lime pastes and lime mortars. Besides, some authors reported the influence of the suspension concentration on consolidation efficacy $[13,14]$.

The present work intends to get more information on the application of lime-nanoparticles for the consolidation of a hypogeum structure which is difficult to treat owing to the influence of humidity and concentration being not well tested and scarcely reported in the literature, for nanoparticles [8, 15]. Physical chemistry experiments focused on the efficacy of consolidating treatments have been carried out with lime particles (chemical species: calcium hydroxide- $\left.\mathrm{Ca}(\mathrm{OH})_{2}\right)$ both in laboratory and in hypogeum environment (catacomb), in order to understand the influence of different microclimatic conditions and to deduce the best nanolime suspension concentration by measuring the microstructure and chemical composition of stone materials differently treated.

\section{Materials and Methods}

The samples examined in the present research come from different materials: laboratory-made samples and stone samples coming from hypogeum environment such as funerary inscriptions fragments.

All the samples have been submitted to treatments by "brush technique" using an alcoholic suspension of hydroxide nanolime (commercial product named NANORESTORE CTS) (NR) with different dilution ratios of isopropyl alcohol and in different environment: room atmosphere (laboratory) and hypogeum.

As regards the catacombs, the references materials and the archaeological samples have been collocated near the cubicle of Gaius (Catacombs of St. Callixtus). The place is characterized by ambient temperature of $16 \pm 1^{\circ} \mathrm{C}$, relative humidity of $94 \% \pm 0.5 \%$, and $\mathrm{CO}_{2}=1200$ ppm., values very different from those measured in laboratory: $T=25 \pm 1^{\circ} \mathrm{C}$; $\mathrm{UR}=55 \% \pm 0.5 \% ; \mathrm{CO}_{2}=880 \mathrm{ppm}$.

2.1. Preparation of Laboratory-Made Samples. In order to evaluate the application of nanolime on hypogeum wall paintings, laboratory-made samples have been realized by using real specimens coming from two different hypogeum sites. The true samples were very small so it has not been possible to treat them directly. All the trials have been carried out on the laboratory-made samples prepared as a microporous stone material able to emulate the structural characteristics of deteriorated real fragments: the constituent materials have been mixed in different ratios in order to realize samples with different characteristics. The following elements have been pressed in an agate mortar to prepare an homogenous powder subsequently added with $20 \mathrm{~mL}$ of distilled water:

(i) 4 g white lime,

(ii) $4 \mathrm{~g}$ silica,

(iii) $2 \mathrm{~g}$ pigment (red-ochre: Zecchi Florence, cinnabar: Kremer pigment).

After 5 minutes of mixing, the aggregate became dense and it has been placed in $5 \mathrm{~cm}$ plates where it dried up during the 48 following hours. In order to verify the property of the samples to simulate natural porosity, the capillary absorption curves of the laboratory-made samples have been compared with those of true specimens. In all, eight samples contained red-ochre pigment and the other eight contained cinnabar pigment (HgS); four cinnabar samples and four red-ochre samples have been treated in laboratory while the other eight in the catacombs. Extra samples have been realized in order to carry out repeatability checks and specific analysis.

2.2. Consolidation Treatment of Laboratory-Made Samples. Laboratory-made samples have been treated with suspensions of nanolime in isopropyl alcohol diluted following methods described in the literature $[16,17]$ in order to improve particles penetration and homogeneous distribution within the samples, according the scheme: 
TABLE 1: Inscription and its inventory number.

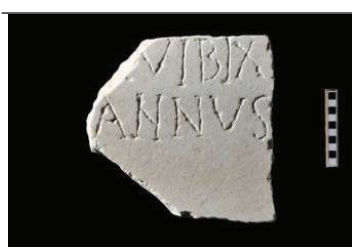

6720

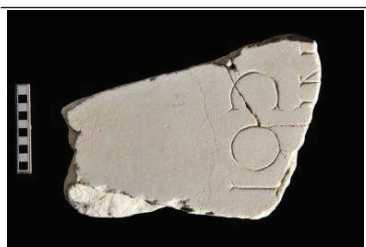

6741

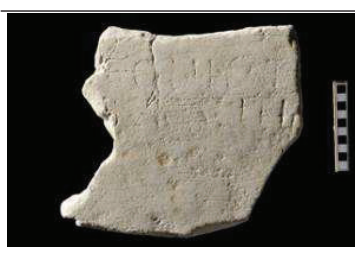

6780

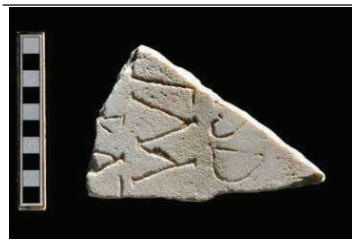

6862

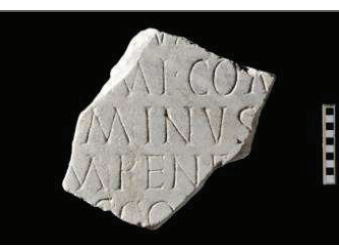

6721

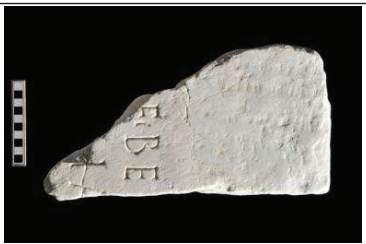

6744

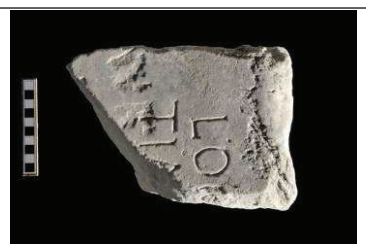

6786

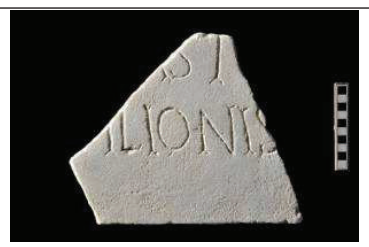

6864

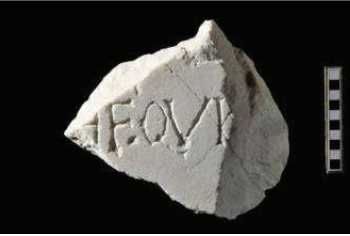

6730

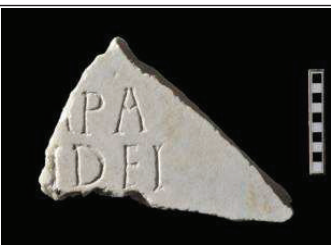

6758

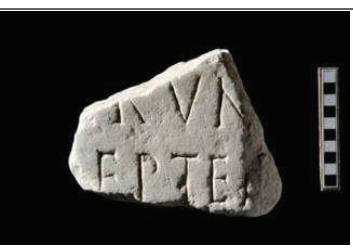

6797

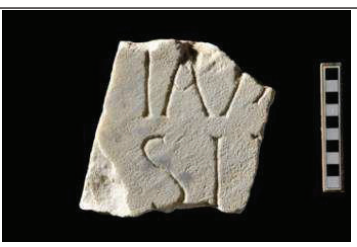

6869

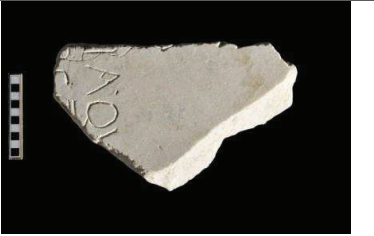

6732

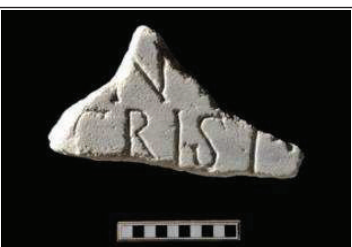

6777

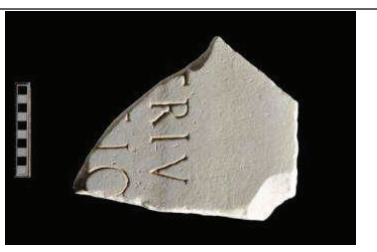

6807

TABLE 2: Water capillary absorption coefficient (CA) $\left(\mathrm{mg} \mathrm{cm}^{-2} \mathrm{~s}^{-1 / 2}\right)$.

\begin{tabular}{|c|c|c|c|c|c|}
\hline \multirow{2}{*}{$\begin{array}{l}\text { Nanorestore } \\
\text { dispersion }\end{array}$} & \multirow{2}{*}{ Number of treatment } & \multicolumn{2}{|c|}{ Laboratory } & \multicolumn{2}{|c|}{ Catacomb } \\
\hline & & Cinnabar & Red-ochre & Cinnabar & Red-ochre \\
\hline \multirow{4}{*}{$1: 5$} & 0 & $0.33 \pm 0.05$ & $0.35 \pm 0.01$ & $0.33 \pm 0.04$ & $0.33 \pm 0.03$ \\
\hline & I & $0.31 \pm 0.07$ & $0.32 \pm 0.03$ & $0.23 \pm 0.03$ & $0.24 \pm 0.03$ \\
\hline & II & $0.25 \pm 0.05$ & $0.27 \pm 0.02$ & $0.2 \pm 0.03$ & $0.18 \pm 0.01$ \\
\hline & III & $0.22 \pm 0.01$ & $0.25 \pm 0.03$ & $0.18 \pm 0.03$ & $0.19 \pm 0.02$ \\
\hline \multirow{4}{*}{$1: 10$} & 0 & $0.36 \pm 0.01$ & $0.33 \pm 0.03$ & $0.33 \pm 0.03$ & $0.34 \pm 0.03$ \\
\hline & I & $0.33 \pm 0.03$ & $0.31 \pm 0.01$ & $0.25 \pm 0.03$ & $0.26 \pm 0.01$ \\
\hline & II & $0.28 \pm 0.05$ & $0.27 \pm 0.02$ & $0.21 \pm 0.04$ & $0.21 \pm 0.05$ \\
\hline & III & $0.23 \pm 0.02$ & $0.24 \pm 0.03$ & $0.19 \pm 0.03$ & $0.18 \pm 0.03$ \\
\hline \multirow{4}{*}{$1: 15$} & 0 & $0.34 \pm 0.01$ & $0.33 \pm 0.05$ & $0.33 \pm 0.02$ & $0.34 \pm 0.02$ \\
\hline & I & $0.32 \pm 0.03$ & $0.33 \pm 0.02$ & $0.27 \pm 0.02$ & $0.27 \pm 0.05$ \\
\hline & II & $0.28 \pm 0.01$ & $0.29 \pm 0.03$ & $0.22 \pm 0.03$ & $0.21 \pm 0.01$ \\
\hline & III & $0.25 \pm 0.03$ & $0.24 \pm 0.03$ & $0.17 \pm 0.05$ & $0.19 \pm 0.01$ \\
\hline \multirow{4}{*}{$\begin{array}{l}\text { Gradual treatment } \\
1: 15,1: 10 ; 1: 5\end{array}$} & 0 & $0.36 \pm 0.02$ & $0.37 \pm 0.01$ & $0.33 \pm 0.01$ & $0.34 \pm 0.01$ \\
\hline & I & $0.32 \pm 0.02$ & $0.33 \pm 0.03$ & $0.28 \pm 0.01$ & $0.27 \pm 0.04$ \\
\hline & II & $0.29 \pm 0.01$ & $0.27 \pm 0.03$ & $0.21 \pm 0.02$ & $0.22 \pm 0.03$ \\
\hline & III & $0.22 \pm 0.03$ & $0.23 \pm 0.02$ & $0.12 \pm 0.03$ & $0.13 \pm 0.03$ \\
\hline
\end{tabular}


TABLE 3: Colorimetric measurements. $\Delta E$ after every treatment compared to the nontreated sample.

\begin{tabular}{|c|c|c|c|c|c|c|}
\hline \multirow{2}{*}{ Laboratory treatments } & \multicolumn{3}{|c|}{ Ochre } & \multicolumn{3}{|c|}{ Cinnabar } \\
\hline & $\Delta E 1$ & $\Delta E 2$ & $\Delta E 3$ & $\Delta E 1$ & $\Delta E 2$ & $\Delta E 3$ \\
\hline Treatment 1:15 & 0.4 & 0.6 & 0.9 & 0.3 & 1.4 & 1.9 \\
\hline Treatment $1: 10$ & 0.6 & 0.9 & 1.1 & 0.6 & 2.5 & 2.8 \\
\hline Treatment $1: 5$ & 0.3 & 1.5 & 2.6 & 0.5 & 3.7 & 3.9 \\
\hline Gradual treatment & 0.2 & 0.4 & 0.8 & 0.4 & 1.0 & 1.6 \\
\hline \multirow{2}{*}{ Catacomb treatments } & \multicolumn{3}{|c|}{ Ochre } & \multicolumn{3}{|c|}{ Cinnabar } \\
\hline & $\Delta E 1$ & $\Delta E 2$ & $\Delta E 3$ & $\Delta E 1$ & $\Delta E 2$ & $\Delta E 3$ \\
\hline Treatment 1:15 & 0.7 & 1 & 0.5 & 1 & 1.1 & 1.2 \\
\hline Treatment $1: 10$ & 0.2 & 0.9 & 0.4 & 1.3 & 1.5 & 1.5 \\
\hline Treatment 1:5 & 0.4 & 1.2 & 1.1 & 1.5 & 1.9 & 1.9 \\
\hline Gradual treatment & 0.5 & 0.6 & 0.8 & 1.8 & 1.2 & 0.4 \\
\hline
\end{tabular}

2 specimens ( 1 red-ochre +1 cinnabar): 3 treatments with isopropyl alcohol suspension diluted $1: 15$,

2 specimens ( 1 red-ochre +1 cinnabar): 3 treatments with isopropyl alcohol suspension diluted $1: 10$,

2 specimens ( 1 red-ochre +1 cinnabar): 3 treatments with isopropyl alcohol suspension diluted 1:5.

The rest of samples have been treated with a "gradual treatment" $(1: 15 ; 1: 10 ; 1: 5)$ using all the different suspensions in order to verify if consolidation or penetration ability of the suspensions is facilitated by gradual increase of concentration. In particular, the "gradual treatment" consists of (a) treatment I: $1: 15$ dilution; (b) treatment II: $1: 10$ dilution; (c) treatment III: $1: 5$ dilution.

The procedure has been undertaken to get the idoneous parameter to achieve an optimal penetration inside the artefact and good rheological properties.

More in detail, it has been chosen to work with different isopropyl alcohol suspension in different times in order to evaluate the efficacy of the dispersion used in the consolidation treatment, the penetration depth of the consolidating product, and the possible chromatic alterations. The final aim has been to choose the optimal suspension for consolidating treatments of historical specimen and inscriptions.

Measurements of capillary absorption, following the standards EN 15801:2009, and colorimetric tests have been carried out after every treatment considering the average of 5 areas on the surface of the samples. Chromatic variations were assessed through colorimetric tests, using a CM-2600d Konica Minolta spectrophotometer. Chromatic values were expressed in the CIE $L^{*} a^{*} b^{*}$ space, where $L^{*}$ is the lightness/darkness coordinate, $a^{*}$ is the red/green coordinate $\left(+a^{*}\right.$ indicating red and $-a^{*}$ green), and $b^{*}$ is the yellow/blue coordinate $\left(+b^{*}\right.$ indicating yellow and $-b^{*}$ blue). The colour difference $(\Delta E)$ of the surface was calculated using the relation $\left(\mathrm{EN} \mathrm{15886:2010)} \Delta E=\left(\left(\Delta L^{*}\right)^{2}+\left(\Delta a^{*}\right)^{2}+\left(\Delta b^{*}\right)^{2}\right)^{1 / 2}\right.$. At the end of the treatments, to verify the penetration of the consolidating product and the possible changes caused by the treatment, the samples have been analysed through scanning electron microscopy and X-ray energy dispersion microanalysis (SEM/EDS, LEO $1450 \mathrm{VP}$-INCA300) on cross-sections obtained from fragments of the specimens embedded in epoxy resin. SEM-EDS was necessary in order to evaluate morphological, structural, and compositional modifications occurred to the material after the consolidation and after the treatment with nanolime suspensions. By using as analytical marker the nanoparticle titanium dioxide (Mknano, $1 \mathrm{wt} \%, 50 \mathrm{~nm}$ ), an additional evaluation was carried out on neoformation crystals inside the interstitial spaces due to carbonation process, penetration depth of the nanolime suspensions, and their distribution inside the section.

The samples prepared as cross-sections have been observed in high-resolution imaging after the application of gold sputter-coated films; backscattered and secondary electrons images have been analysed.

The set of information obtained about the best treatment has been used for the treatment of the inscriptions.

2.2.1. The Inscriptions. More in detail, the analytical work has been applied to marble fragments derived from 15 selected stones among 190 funerary inscriptions placed in Catacombs of St. Callixtus. Before the restoration process all the inscriptions presented (a) biological growth, (b) soil deposits, (c) mortar residues, and (d) concretions and carbonate patinas. Before the consolidation treatment, the fragments have been cleaned and disinfected with hydrogen peroxide (120-vol). The mineral-petrographic features of the inscriptions have been analysed through thin-section optical microscope and X-ray Diffraction (XRD, Philips PW 1830 powder XRD with a $\mathrm{Cu}-\mathrm{K} \alpha$ source).

Preservation status has been examined through portable optical microscope observations (Alpha Instruments) and through pulverization measurements of the surface, peeling test, or "scotch tape test" (STT). This last is defined as a method to quantify the adhesion of a surface or near-tosurface layer to a substrate.

The inscriptions fragments object of the treatments is reported in Table 1 where a metric scale indicates $10 \mathrm{~cm}$.

2.2.2. Consolidating Treatment of the Inscriptions. On the base of the preliminary analysis, 8 inscriptions have been selected by excluding those with good macroscopic preservation status. After the optical microscope observations the 


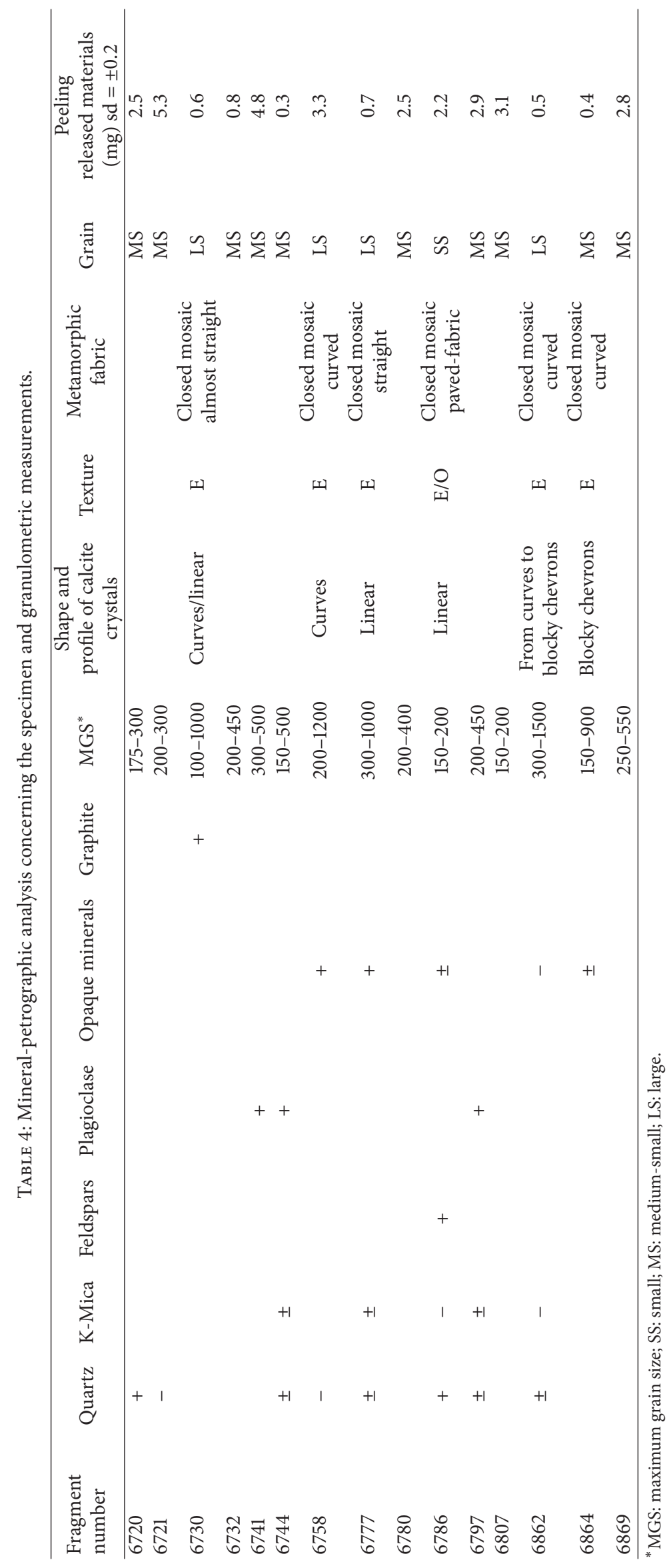


TABLE 5: Absorption degrees referring to the laboratory treatments, carried out on sample $\mathbf{6 7 2 1}$.

\begin{tabular}{lcccc}
\hline & Straight line & $\mathrm{mL}$ at 5 minutes & $\mathrm{mL}$ at 30 minutes & \\
\hline Nontreated & $y=0.011 x$ & 0.06 & 0.36 & 0.03 \\
$1^{\circ}$ treatment & $y=0.012 x$ & 0.06 & 0.36 & 0.03 \\
$2^{\circ}$ treatment & $y=0.012 x$ & 0.06 & 0.36 & 0.03 \\
$3^{\circ}$ treatment & $y=0.0072 x$ & 0.04 & 0.22 & 0.02 \\
\hline
\end{tabular}

TABLE 6: Absorption degrees referring to the catacombs treatments, carried out on sample 6741.

\begin{tabular}{llccc}
\hline & Straight line & $\mathrm{mL}$ at 5 minutes & mL at 30 minutes & AG \\
\hline Nontreated & $y=0.0625 x$ & 0.3125 & 1.875 & 0.16 \\
$1^{\circ}$ treatment & $y=0.0356 x$ & 0.178 & 1.068 & 0.09 \\
$2^{\circ}$ treatment & $y=0.0327 x$ & 0.1635 & 0.981 & 0.08 \\
$3^{\circ}$ treatment & $y=0.0247 x$ & 0.1235 & 0.741 & 0.06 \\
\hline
\end{tabular}

TABLE 7: Starting and ending absorption degrees concerning laboratory-treated fragments.

\begin{tabular}{lcc}
\hline Sample & Starting AG & Ending AG \\
\hline 6758 & 0.19 & 0.12 \\
6780 & 0.32 & 0.30 \\
6797 & 0.05 & 0.04 \\
\hline
\end{tabular}

TABLE 8: Starting and ending absorption degrees concerning catacomb-treated fragments.

\begin{tabular}{lcc}
\hline Sample & Starting AG & Ending AG \\
\hline 6786 & 0.16 & 0.05 \\
6807 & 0.14 & 0.03 \\
6869 & 0.10 & 0.02 \\
\hline
\end{tabular}

inscriptions have been split in two homogeneous groups to proceed with the consolidating treatment in particular: (a) fragments treated in laboratory: 6721, 6758, 6780, and 6797; (b) fragments treated in the catacombs: 6741, 6786, 6807, and 6869.

The consolidating treatment, by "brush technique," has been carried out using three Nanorestore (NR) dispersions:

treatment I: dilution $1: 15$ in isopropyl alcohol,

treatment II: dilution 1:10 in isopropyl alcohol,

treatment III: dilution 1:5 in isopropyl alcohol.

The applications have been spaced out (period of 30 days) to let the carbonation process end. Before the application of $50 \mathrm{~mL}$ of $\mathrm{NR}$, the surface has been slightly wet to facilitate the penetration of the product, due to the hydrogen bonds that NR can form with water thin surface layer.

After each treatment, capillary absorption measurements with low pressure (following the standard UNI NORMAL 44-93) have been carried out to verify the decreasing of water absorption, directly correlated to the macroporosity reduction after the consolidating treatment. In order to verify the carbonation process completeness, phenolphthalein microchemical test has been carried out.

\section{Results of the Experimentation}

3.1. Laboratory-Made Samples. Water capillary absorption test is very useful to evaluate the grade of consolidation treatments: higher is the reduction of water capillary absorption, major is the possibility to get smaller pores, up to realize pores that allow only interaction between stone and water vapour. Water capillary absorption curve has been obtained by measuring the absorbed water amount $(A)$ during the time, according to the equation $A=\left(m_{i}-m_{0}\right) / S$, where $m_{i}$ is the weight of the soaked treated sample at time $=t$ and $m_{0}$ is the weight of the dried sample at time $=0 . S$ is the surface area of the sample kept in contact with the water soaked filter paper. By plotting $A$ versus $t^{1 / 2}$ (s) the initial slope of the curves is the water capillary absorption coefficient, CA $\left(\mathrm{mg} \mathrm{cm}^{-2} \mathrm{~s}^{-1 / 2}\right)$.

As concerns the untreated sample, the absorption is not high and the maximum of CA value is achieved during the first 30 minutes. This result can be due to the limited thickness of the sample $(1 \mathrm{~cm})$.

In Table 2, CA values for different treatments are reported, and from the discussion of the data, it can be observed that after the second treatment in laboratory, the samples show a high CA value and low consolidation effect, while, in the samples examined in catacombs, the capillary absorption is lower and in the same samples is considerably reduced after the second treatment. For the most part of the samples treated in laboratory, it is not possible to observe a real absorption decrease, because the absorption curves after two treatments confirm the absorption curve trend in nontreated sample. The gradual treatment induces a higher CA decrease, by indicating that this procedure can be validated for its application. Any different behaviour is due to the presence of the two pigments.

Colorimetric data show a small chromatic variation mainly in the laboratory-treated samples, realized with cinnabar. The $\Delta E$ values variation is due to the difference of colour tone of the surface and in particular to the increase of the parameters " $a$ " and " $b$ " whose different ratios lead to yellow-orange tones and this coincides with a brightness increase for the treatment with 1:5 dispersion (Table 3). 


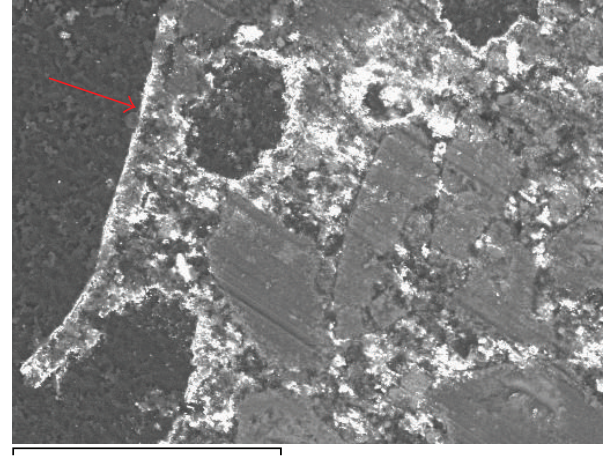

$200 \mu \mathrm{m}$
Electron image 1

(a)

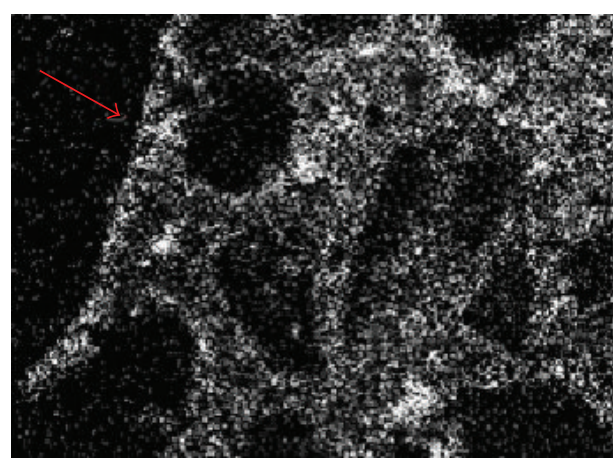

Ti Kal

(b)

FIGURE 1: SEM image in back scattered electrons and element mapping of Titanium. Dilution 1:5/catacomb treatment. The EDS mapping imaging has been enhanced by considering three pixels for each point.

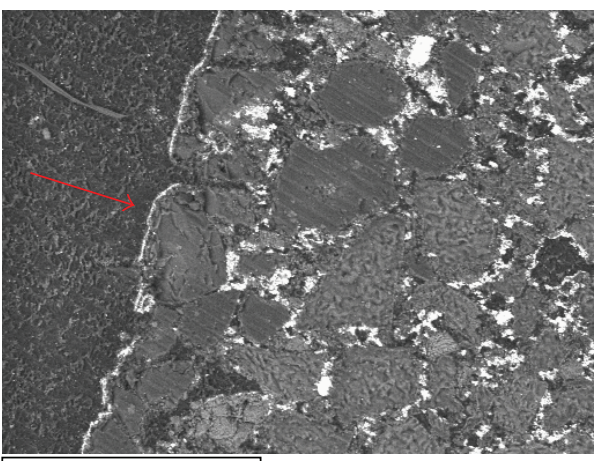

$400 \mu \mathrm{m}$
Electron image 1

(a)

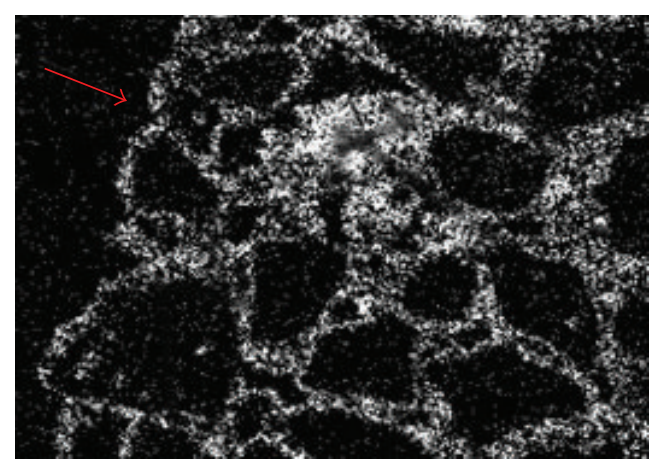

Ti Ka1

(b)

FIGURE 2: SEM image in back scattered electrons and element mapping of Titanium. Dilution mix/catacomb treatment. The EDS mapping imaging has been enhanced by considering three pixels for each point.

In every case, the surface colour change due to NR applications in various treatments, is less than $\Delta E=5$ where the change is difficult to observe [18].

Scanning Electron Microscopy (SEM) observations and the EDS X-ray detection highlighted the penetration of the consolidating product inside of the specimens. To characterize the penetration depth, $\mathrm{TiO}_{2}$ as marker has been used.

Alcoholic suspensions penetrate independently from the used suspension concentration and as a function of the different porosimetric features of the samples as observed on the cross-section SEM images with back scattered detector. The solution concentration increasing causes a small thickening of the superficial consolidation layer as observable in Figures 1 and 2 where the left images represent the EDS-Ti mapping. The calcite crystals neoformated are regular-shaped and regular-sized: $400-500 \mathrm{~nm}$.

The gradual treatment allows obtaining deeper penetration of consolidant product inside the stone.

It is accepted, in the specific literature, that diluted isopropyl alcohol dispersions of calcium hydroxide particles show a slower rate of agglomeration (and, therefore, slower sedimentation rates) in comparison to the more concentrated; this facilitates the penetration and reduces the tendency for a white film to form on surfaces to be consolidated $[19,20]$.

3.2. Inscriptions. A preliminary analysis has been carried out on all the inscriptions sample in order to evaluate those to be processed in the laboratory, in Table 4 the characteristic elements of each fragment are reported.

By analyzing the data reported, it is possible to observe significant differences such as the fragments 6720, 6732, $6744,6777,6862$, and 6864 that show a modest pulverization phenomenon (released materials $<1 \mathrm{mg}$ ). Based on these results, the fragments have been divided in two homogenous groups considering the mineral-petrographic characteristics. Every group has been treated in a different environment: catacomb and laboratory. Low-pressure absorption has been measured on each selected inscription, after the treatment. The obtained results show similar trends for the inscriptions treated in the catacombs as well as inscriptions treated in laboratory. Figures 3 and 4 show the results regarding inscription $n^{\circ} 6721$ (in laboratory) and inscription $n^{\circ} 6741$ (in catacomb), while data referring to the other inscriptions are 


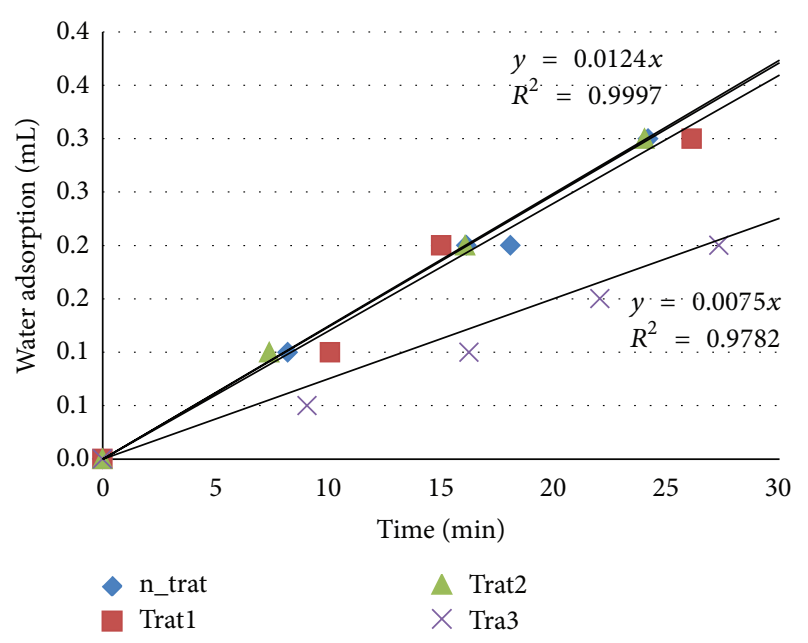

FIgURE 3: Sample 6721 (in laboratory), low-pressure absorption, Italian standards UNI NORMAL 44-93. N_trat: absorption before the treatment, $\operatorname{trat} 1=1: 15$, trat $2=1: 10$, and trat $3=1: 5(\mathrm{STD}=0.05)$.

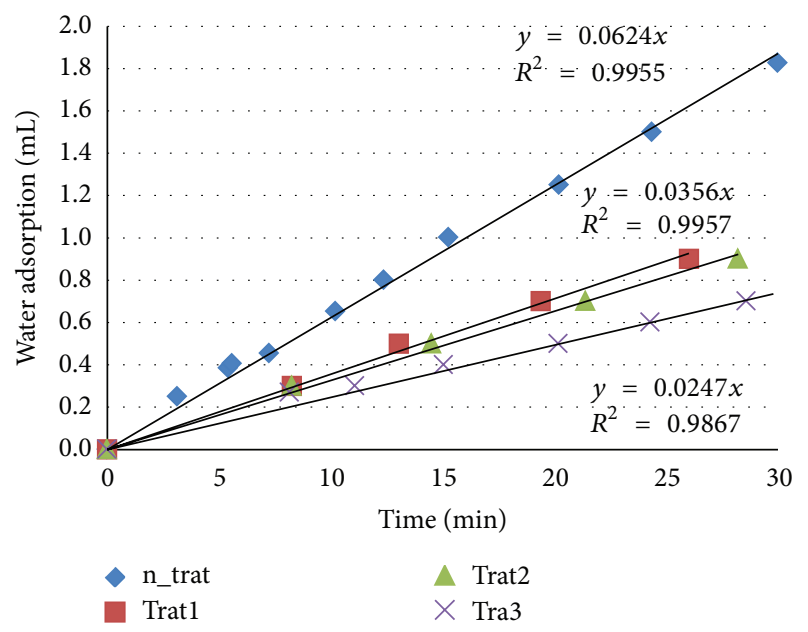

FIgURE 4: Sample 6741 (in catacombs), low pressure absorption, Italian standards UNI NORMAL 44-93. n_t: absorption before the treatments, trat $=1: 15$, trat $2=1: 10$, and trat $3=1: 5(\mathrm{STD}=0.05)$.

summed up in Tables 4 and 5 . Absorption has been monitored at different times as illustrated in Figure 3.

The reaction behaviour has been highlighted using the trend curve represented by the best fit line. The different trends of the samples have been described by straight lines or by second-degree polynomials. Figure 3 shows a decrease of the absorption and a consequential decrease of the porosity but only after the third treatment.

Based on these curves it is possible to calculate the water absorption degree (AG) which summarizes the monitored absorption.

Table 5 shows AG values related to the different treatments and the value of straight-line slopes $(m)$.

Absorption curves trend and calculated AG highlight how both after the first and after the second treatment the inscription porosity is not decreased. The third treatment shows a large absorption reduction appreciable in the graph where the curve slope goes from $1.1 \times 10^{-2}$ of the nontreated sample to $0.7 \times 10^{-2}$ after the $3^{\circ}$ treatment, in agreement with AG values.

The study on capillary absorption related to inscription 6741 , treated in the catacombs, produced the data reported graphically in Figure 4 and numerically in Table 6.

Table 6 shows AG values related to the different treatments and the value of straight-line slopes $(m)$.

The experimental values show that after the first treatment, the capillary absorption is consistently reduced and remains stable between the first and second treatment while the third treatment causes an additional absorption reduction and consequently a porosity reduction ( $1 / 3$ lower).

As concerns the other fragments of the analyzed inscriptions the DG data are reported in Tables 7 and 8.

The data for the catacomb treatment show a major absorption reduction with respect to laboratory.

\section{Discussion}

After treatments were carried out on cinnabar and ochre samples, capillary absorption allowed characterizing the efficacy of the different treatments. Based on the obtained results it is possible to consider that, regarding laboratorytreated samples, by using $1: 15,1: 10$, and $1: 5$ dispersion and dispersion-mix (1:15, 1:10 and 1:5) absorption decrease is only observed after the third application. As concerns the catacomb-treated samples, treatments 1:15 does not show a capillary absorption decrease but only a slowdown of the absorption during the first minutes of the analysis. Treatments carried out with higher concentrations $(1: 10,1: 5$, and mix) show a slowdown of the capillary absorption even after the first application and, in some cases, a real decrease. After the second and the third application of the suspension, the slowdown increases. More concentrated solutions seem to work better than diluted ones as they allow the aggregation among the molecules of NR resulting in a more efficient consolidation.

These clear different results between the two environments involved are justified by climatic influence conditions on the carbonation process which is facilitated and accelerated by thermohygrometric conditions in the hypogeum site. Colorimetric tests pointed out, especially in treated cinnabar, light chromatic variations from red to yellow-orange tones. Different suspension concentrations, apparently, do not affect chromatic variations. To this variation no brightness mutation is correspondent and it allows more excluding the formation of white layers on the surface. Chromatic variation is due to "brush technique" applied on the surfaces. Scanning electron microscopy analysis showed the consolidant penetration into the samples. The use of suspension-mix prevents the formation of consolidant thickenings in the outer layers; moreover the mix is suitable for the further consolidation of the inscriptions.

The obtained results explain how the consolidation treatment caused an absorption decrease in every inscription. The differences regarding this decrease result from the different chemical-physical features (structural characteristics, 
main components, and porosity) of the analyzed fragments. Absorption reductions among the I, the II, and the III treatment are clearer in the catacomb-treated samples (where, in some cases, it is possible to observe a variation of the slope ( $m$ ) already after the I treatment) than in laboratory-treated ones.

Regarding the treatments carried out in laboratory, absorption decrease is observed only after the III treatment with diluted $1: 5$ suspension. The hypothesis on an incomplete carbonation process regarding the previous processes $(1: 15$, $1: 10)$ is confirmed by the phenolphthalein tests, carried out after every single treatment. Incomplete carbonation occurs in the case of more diluted dispersions probably due to NR in not sufficient amounts, so it accounted for a much slower kinetics of the carbonation process. In the case of more diluted dispersion there is the possibility to recover the suitable surface concentration of NR by repeating the treatment. So really the carbonation more than less complete is slower.

The "delay" of the carbonation process or the failure to be completed is certainly related to the low humidity in the working environment, as such reaction between calcium hydroxide $\left(\mathrm{Ca}(\mathrm{OH})_{2}\right)$ and carbon dioxide $\left(\mathrm{CO}_{2}\right)$ takes place only in solution hence causing the long duration of the process.

The repeated application of the suspensions diluted $1: 15$ and $1: 10$ causes a consolidation comparable with the application of the mix.

\section{Conclusions}

The development of the work, even if preliminary, highlights the fundamental relevance of the knowledge and acquaintance of all the environmental, chemical, and physical parameters involved in any restoration approach before any application of new materials with restoration scope.

The studied procedure of nanolime application can help conservators working on historic stone structures in hypogea using less water for consolidation in a time-effective manner.

Chemical-physical compatibility of consolidating materials with original structures is a fundamental premise in the conservative procedures and in particular in hypogeum sites.

Using nanolime in hypogeum environments allows to restore structural balance and mechanical properties of the artefacts in order to establish the more suitable environmental conditions and usability and to respect the original and the future conservation. In situ treatment inside the catacombs turned out to be the most efficient one thanks to the constant humidity and to the structures which facilitate the carbonation process. The best application method of the consolidating product starts with the use of a very diluted dispersion $(1: 15)$ and goes on with the application of the concentrated ones $(1: 10,1: 5)$ taking always into account the degradation state of the artefact. The validated method reduces the stone porosity and does not modify the surface color.

The positive results obtained yield two important considerations for the future: the first is the necessity of the use of diagnostic procedure tailored for any monument that could be realized with no sophisticated technologies but with the knowledge of the materials chemistry and the second is the proposition of modern procedure for the application of the new material for restoration hoping for the extension of an enlargement of the multidisciplinary scientific studies.

\section{Conflict of Interests}

The authors declare that there is no conflict of interests regarding the publication of this paper.

\section{References}

[1] V. Daniele, G. Taglieri, and R. Quaresima, "The nanolimes in cultural heritage conservation: characterisation and analysis of the carbonatation process," Journal of Cultural Heritage, vol. 9, no. 3, pp. 294-301, 2008.

[2] N. Cardinale, G. Rospi, and A. Stazi, "Energy and microclimatic performance of restored hypogeous buildings in south Italy: the "Sassi" district of Matera," Building and Environment, vol. 45, no. 1, pp. 94-106, 2010.

[3] F. Piacenti, "Chemistry for the conservation of the cultural heritage," Science of the Total Environment, vol. 143, no. 1, pp. 113-120, 1994.

[4] P. D’Armada and E. Hirst, "Nano-lime for consolidation of plaster and stone," Journal of Architectural Conservation, vol. 18, no. 1, pp. 63-80, 2012.

[5] V. Daniele and G. Taglieri, "Synthesis of $\mathrm{Ca}(\mathrm{OH}) 2$ nanoparticles with the addition of Triton X-100. Protective treatments on natural stones: preliminary results," Journal of Cultural Heritage, vol. 13, no. 1, pp. 40-46, 2012.

[6] L. Dei and B. Salvadori, "Nanotechnology in cultural heritage conservation: nanometric slaked lime saves architectonic and artistic surfaces from decay," Journal of Cultural Heritage, vol. 7, no. 2, pp. 110-115, 2006.

[7] H. Hosono, Y. Mishima, H. Takezoe et al., Nanomaterials From Research to Applications, Elsevier, London, UK, 2006.

[8] P. López-Arcea, L. S. Gomez-Villalbaa, L. Pinhob, M. E. Fernández-Vallec, M. Álvarez de Buergoa, and R. Forta, "Influence of porosity and relative humidity on consolidation of dolostone with calcium hydroxide nanoparticles: effectiveness assessment with non-destructive techniques," Materials Characterization, vol. 61, no. 2, pp. 168-184, 2010.

[9] S. Sanchez-Moral, L. Luque, S. Cuezva et al., "Deterioration of building materials in Roman catacombs: the influence of visitors," Science of the Total Environment, vol. 349, no. 1-3, pp. 260-276, 2005.

[10] P. Albertano, "Deterioration of Roman hypogea by epilythic cyanobacteria and microalgae," in Science and Technology For the Safeguard of Cultural Heritage in Mediterranean Basin, A. Guarino et al., Ed., vol. 2, pp. 1303-1308, CNR Editions, Palermo, Italy, 1998.

[11] A. El-Turki, R. J. Ball, and G. C. Allen, "The influence of relative humidity on structural and chemical changes during carbonation of hydraulic lime," Cement and Concrete Research, vol. 37, no. 8, pp. 1233-1240, 2007.

[12] A. El-Turki, M. A. Carter, M. A. Wilson, R. J. Ball, and G. C. Allen, "A microbalance study of the effects of hydraulicity and sand grain size on carbonation of lime and cement," 
Construction and Building Materials, vol. 23, no. 3, pp. 14231428, 2009.

[13] V. Daniele and G. Taglieri, "Nanolime suspensions applied on natural lithotypes: the influence of concentration and residual water content on carbonatation process and on treatment effectiveness," Journal of Cultural Heritage, vol. 11, no. 1, pp. 102106, 2010.

[14] R. Giorgi, L. Dei, M. Ceccato, C. Schettino, and P. Baglioni, "Nanotechnologies for conservation of cultural heritage: paper and canvas deacidification," Langmuir, vol. 18, no. 21, pp. 81988203, 2002.

[15] G. Baldi, M. Camaiti, L. Luvidi, C. Mazzotta, and A. M. Mecchi, "Caratteristiche fotocalitiche e antibatteriche dei nanomateriali," in Arkos, Scienza e Restauro, Luglio/settembre, 2011.

[16] I. Natali, M. L. Saladino, F. Andriulo et al., "Consolidation and protection by nanolime: Recent advances for the conservation of the graffi ti, Carceri dello Steri Palermo and of the 18th century lunettes, SS.Giuda e Simone Cloister, Corniola (Empoli)," Journal of Cultural Heritage, 2013.

[17] L. Dei, F. Bandini, A. Felici et al., "Preconsolidation of pictorial layers in frescoes, the high performance of CSGI's method based on nanolime evaluated by OPD team in Agnolo Gaddi's La Leggenda della Vera Croce, Santa Croce, Firenze," in Proceedings of the 23rd International Congress 'Il consolidamento degli apparati architettonici e decorativi. Conoscenze, Orientamenti, Esperienze', pp. 217-224, Venezia, Italy, 2007.

[18] G. Vigliano, "Graffiti and antigraffiti project," 2002, http://www .icr.beniculturali.it.

[19] E. Hansen, E. Doehne, J. Fidler et al., "A review of selected inorganic consolidants and protective treatments for porous calcareous materials.," Reviews in Conservation, vol. 4, pp. 1315, 2003.

[20] R. Giorgi, L. Dei, and P. Baglioni, "A new method for consolidating wall paintings based on dispersions of lime in alcohol," Studies in Conservation, vol. 45, no. 3, pp. 154-161, 2000. 

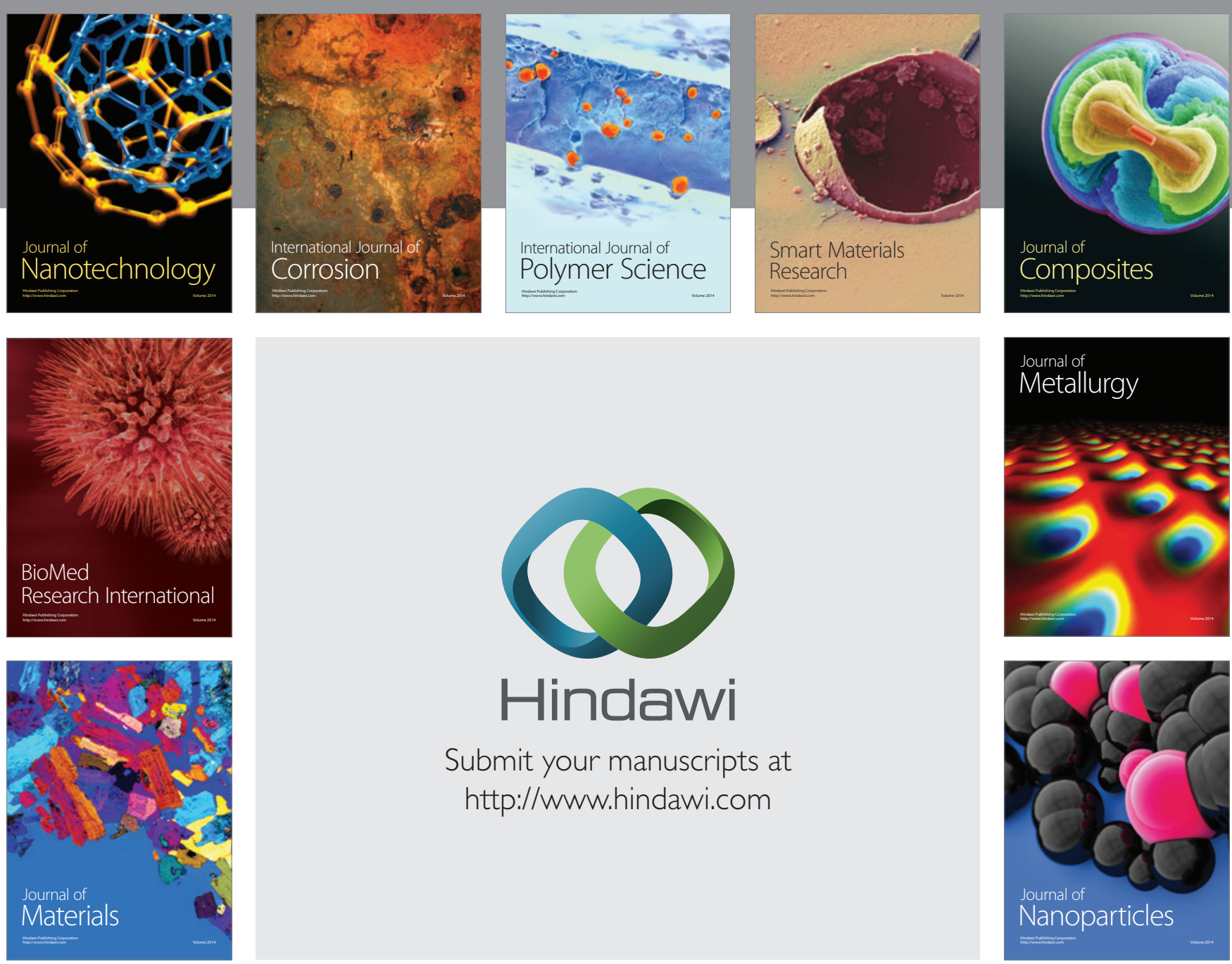

Submit your manuscripts at http://www.hindawi.com
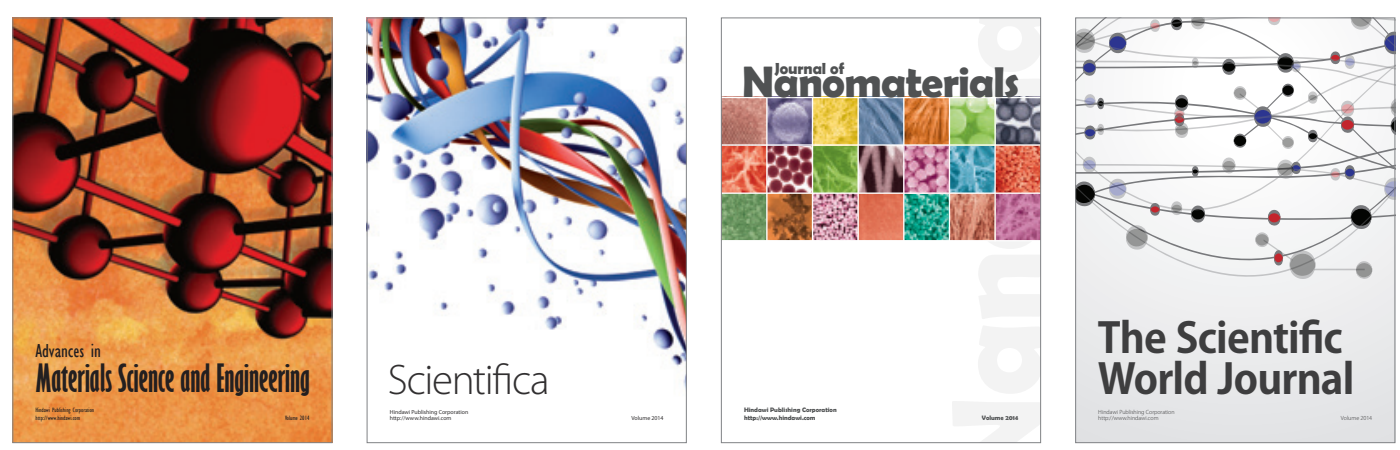

\section{The Scientific World Journal}
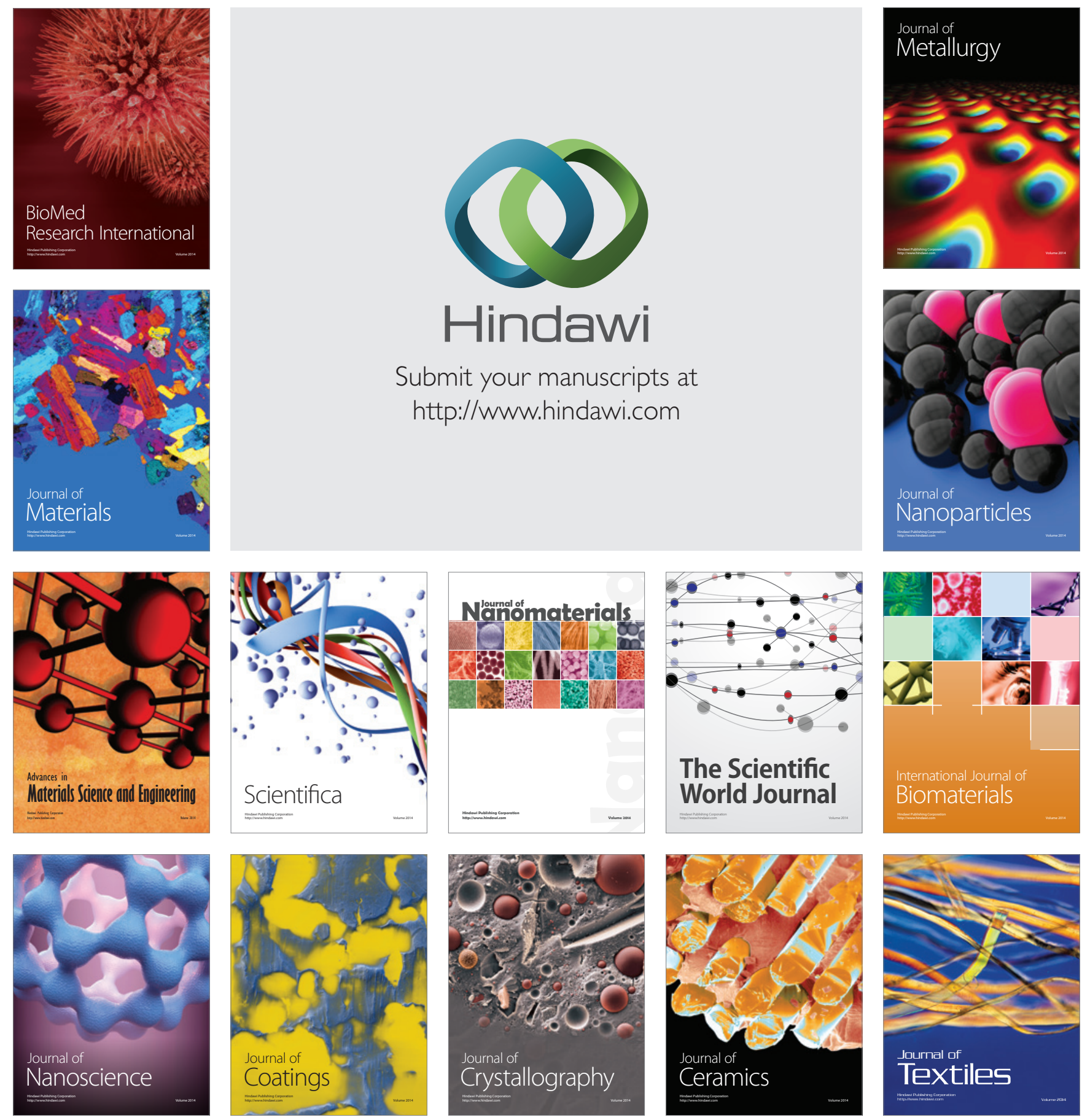